\title{
CORRIGENDUM
}

\section{Molecular mechanisms of Escherichia coli pathogenicity}

Matthew A. Croxen and B. Brett Finlay

Nature Reviews Microbiology 8, 26-38 (2010)

On page 31 of this article, in the third paragraph of the section 'Enterotoxic Escherichia coli', the sentence "This leads to increased intracellular levels of cyclic GMP and activates the cystic fibrosis transmembrane conductance regulator (CFTR), resulting in impaired absorption of $\mathrm{Na}^{+}$and $\mathrm{H}_{2} \mathrm{O}$ efflux into the lumen ${ }^{63}$." should have read "This leads to increased intracellular levels of cyclic GMP, resulting in impaired $\mathrm{Na}^{+}$absorption, as well as activation of the cystic fibrosis

transmembrane conductance regulator (CFTR) ${ }^{63}$." The authors apologize to the readers for any misunderstanding caused. 